\title{
A RARE CASE REPORT OF ASYMPTOMATIC SEVERE PRIMARY PULMONARY HYPERTENSION IN PREGNANCY
}

\author{
Venus Bansal11, Niti Poonia², Jaspreet Kaur 3
}

${ }^{1}$ Co-Ordinator and HOD, Department of Obstetrics and Gynaecology, SPS Hospitals, Ludhiana.

${ }^{2}$ DNB Third Year Student, SPS Hospitals, Ludhiana.

3 Senior Medical Officer, SPS Hospitals, Ludhiana.

HOW TO CITE THIS ARTICLE: Bansal V, Poonia N, Kaur J. A rare case report of asymptomatic severe primary pulmonary hypertension in pregnancy. J. Evolution Med. Dent. Sci. 2018;7(06):813-815, DOI: 10.14260/jemds/2018/185

\section{PRESENTATION OF CASE}

Patient, Mrs. X, first presented to us in OPD as primigravida in her seventh month of pregnancy after being referred by a private practitioner. She had no complaints apart from occasional palpitations that she had experienced right from her childhood. Her obstetrical investigations were normal. On examination, there was grade 4 pansystolic murmur in tricuspid area. Echo suggested Severe Pulmonary Arterial Hypertension with Severe Tricuspid Regurgitation, Left Ventricular Ejection Fraction $47 \%$ and dilated Right Atrium, Right Ventricle and Pulmonary Artery. Other investigations for the cause of pulmonary hypertension were normal.

A cardiologist's opinion was sought and since the patient was asymptomatic no intervention or medication was advised. Patient was on regular weekly follow-up with us and fortnightly with cardiologist thereafter.

Patient and family were advised for elective caesarean between 34 - 36 weeks of her pregnancy (she stayed at a distance of approx. $70 \mathrm{kms}$ from the hospital). They wanted to wait for normal delivery, as she was asymptomatic. She was counselled for benefits of spontaneous onset of labour. At 37 weeks of gestation, she presented to us in labour with leaking P/V. At the time of admission, her Bishop's score was very poor. Expecting a prolonged labour, she was counselled for caesarean. An emergency caesarean was done for her under epidural anaesthesia under constant supervision of senior anaesthesiologist, cardiologist and intensivist. Intraoperative period was uneventful, and patient shifted to Intensive Care Unit. Postoperatively, patient was managed with IV fluids (to maintain PR > 70 and SBP $>130 \mathrm{mmHg}$, Inj. Antibiotics (Inj. Augmentin), Inj. Clexane (LMWH); and pain was managed with epidural infusions. Male Baby was born $2.3 \mathrm{~kg}$ in weight with immediate cry. Echo of newborn was normal and shifted to mother's side.

Next day patient developed bigeminy rhythm that persisted for 20 - 30 minutes on ECG. Blood gas analysis revealed low potassium levels. Echo was repeated and there was no interval change in the findings. Potassium and magnesium replacement was done and the abnormal pattern on ECG resolved. Patient shifted to ward on $2^{\text {nd }}$ postoperative day. Rest of the post-operative period for the patient was uneventful. Patient was discharged on $4^{\text {th }}$ postoperative day.

'Financial or Other Competing Interest': None.

Submission 06-09-2017, Peer Review 18-01-2018,

Acceptance 27-01-2018, Published 05-02-2018.

Corresponding Author:

Dr. Venus Bansal,

\#253-A, Model Town Extension,

Ludhiana.

E-mail:dr_venus@rediffmail.com

DOI: $10.14260 /$ jemds $/ 2018 / 185$
Patient is on routine follow-up with us and till date is doing well without any symptoms or deterioration.

Pregnancy in women with pulmonary hypertension (PH) is a rare, but amongst the highest risk pregnancies. Incidence of pulmonary hypertension is 1: 100000 maternities.(1) $\mathrm{PH}$ is regarded as a contraindication of pregnancy. At times woman become pregnant despite being advised against pregnancy or $\mathrm{PH}$ is newly diagnosed during pregnancy as was in our case. $\mathrm{PH}$ is defined at cardiac catheterisation as mean pulmonary artery pressure (PAP) of $>25 \mathrm{mmHg}$ at rest.

\section{DIFFERENTIAL DIAGNOSIS}

\section{Cardiac Diseases}

- Congenital: Left-to-right shunts (e.g. atrial septal defect, ventricular septal defect, persistent ductus arteriosus).

- Acquired: Left ventricular failure, mitral valve disease, left atrial thrombus or tumour, respiratory diseases.

\section{Respiratory Diseases}

- Chronic obstructive pulmonary diseases (e.g. chronic bronchitis, emphysema, asthma, bronchiectasis).

- Chronic parenchymal lung diseases (e.g. pulmonary fibrosis, pneumoconiosis, extrinsic allergic alveolitis).

- Cystic fibrosis.

- Obstructive sleep apnoea.

- $\quad$ Thoracic cage abnormalities.

\section{Pulmonary Thromboembolism}

- Pulmonary vasculitides (e.g. lupus erythematosus, scleroderma, rheumatoid disease).

- Hyperviscosity syndromes (e.g. multiple myeloma).

- Infections (e.g. human immunodeficiency virus, schistosomiasis).

- Portal hypertension.

- Cirrhosis.

- Pulmonary veno-occlusive disease.

- Primary pulmonary hypertension including drug-related (e.g. appetite suppressants, cocaine).

\section{Management}

Factors making PH a High Risk for Pregnant Female-

1. Women with $\mathrm{PH}$ has an overloaded right ventricle that struggle to cope with the additional cardiovascular demands of pregnancy.

2. Fall in systemic vascular resistance may worsen the right to left shunt seen in Eisenmenger syndrome.

3. The hormonal and haematological consequences of pregnancy are thought to be additional insults to pulmonary circulation.

4. Increased venous return may trigger severe vasoconstriction that leads to decreasing venous return to the 
left side of heart further and resulting in fall in systemic blood pressure, which may be fatal despite vigorous attempts of resuscitation.

Maternal mortality was reported to be $30 \%$ - 56\% $(1990)^{(2)}$ and $10 \%-25 \%(3)$ in more recent case series. The time of highest risk is early postnatal period. Refractory right heart failure is reported as the commonest cause of death. Poor foetal outcomes have been reported due to preterm deliveries $(85 \%-100 \%)$, foetal growth restriction $(3 \%$ $33 \%)$ and foetal and neonatal loss (7\% - 13\%). Foetal outcome is even more poorer, if mother has congenital cyanotic cardiac disease. Maternal oxygen saturation below $85 \%$ is predictive of poor pregnancy outcome with live birth rate of $12 \%$.

\section{Follow-up of Pregnancy with pH-}

1. OPD visits weekly by obstetric consultant.

2. Every 2 weekly by cardiologist or combined cardiac obstetric clinics.

\section{At every visit points to be noted are-}

- Signs and symptoms of cardiac decompensation.

- Assessment of resting oxygen saturation.

- ECG.

- Detailed assessment of ventricular function by regular echocardiography.

- Assessing need for anticoagulation therapy and if anticoagulation already given, then anti-Xa levels to be monitored.

- $\quad$ Pulmonary vasodilator therapy as needed (Table 1).

- Multidisciplinary review at 32 to 34 weeks is needed in such cases.

\section{Obstetrical Management-}

1. Planned caesarean at 34 weeks.

2. If vaginal birth is attempted, appropriate length of second stage should be discussed.

3. Type of analgesia.

4. Prophylaxis for $\mathrm{PPH}$.

5. Thromboprophylaxis in post-partum period.

6. Echo in post-partum to assess cardiac function.

7. Need and availability of high dependency unit.

8. Check for availability of advance care with ventilator and ECMO availability.

\section{Thromboprophylaxis for Pregnancy with $\mathrm{PH}$ -}

Idiopathic $\mathrm{PH}$ is characterised by hypertrophy, vasoconstriction and thrombus formation in pulmonary microvasculature. Additionally, pregnancy has 6-fold increased risk of thrombosis. In puerperium, this risk is further increased. Paradoxical embolism (due to right to left shunt) and risk of arrhythmias make these patients candidates for thromboprophylaxis. There is no evidence of optimal anticoagulation therapy in Eisenmenger patients.

\section{Mode of Delivery(4)}

Ideal mode of delivery for pregnant female with $\mathrm{PH}$ is still uncertain. Normal delivery has the advantage of less haemodynamic changes, haemorrhage, infection, venous thromboembolism. A planned caesarean can time a delivery for optimal conditions. In case a trial of normal delivery is attempted, spontaneous labour is better than induction and in labour second stage should be cut short. For any deterioration of symptoms delivery is immediately planned.

\section{Labour Analgesia}

Cardiac output increases by $12 \%$ during labour and further $20 \%$ in contraction. Moreover, there is increase in heart rate and blood pressure due to anxiety and pain. Labour analgesia is offered to these patients, as it lowers the variation in vitals. Nerves of T10 to L1 root levels are blocked before entering into the spinal cord to give caudal, low epidural and low arachnoid blocks.

For anaesthesia during caesarean, Epidural is a preferred choice. GA has deleterious effect of positive pressure ventilation on the postoperative respiratory function. However, if GA is given due to some reason, it offers the advantage of intraoperative monitoring of transesophageal echocardiography.

\section{Management of Third Stage of Labour-}

In a normal pregnancy uterotonics reduce PPH by $50 \%$, but they are not very safe in cardiac patients. There are side effects of uterotonics in pregnant patients with $\mathrm{PH}$ -

1. Ergometrine causes vasoconstriction (especially in coronary arteries) and hypertension.

2. Oxytocin bolus increases pulmonary vascular resistance causing hypotension and tachycardia.

RCOG recommends Low Dose (12-40 $\mathrm{mU} / \mathrm{min})$ Syntocinon Infusion for upto 4 hours or longer, if necessary(5)

Post-delivery - Maximally effective contraception is advised to the patient.

\section{Genetic Counselling}

BMPR2, ACVRL1, KCNK3, CAV1 are some pathogenetic variant of the gene of familial pulmonary hypertension. Each child of affected individual has a 50\% risk of inheriting the mutant. Prenatal testing is possible if variant has been defined.

\begin{tabular}{|c|c|}
\hline Sildenafil & $\begin{array}{c}\text { Inhibits cGMP specific phosphodiesterase type } \\
\text {, decreasing the degradation of cGMP and } \\
\text { leading to local release of nitric oxide and } \\
\text { vasodilatation }\end{array}$ \\
\hline Bosentan & \begin{tabular}{|c|} 
Competitive antagonist of endothelin-1 \\
Teratogenic, so contraindicated in pregnancy
\end{tabular} \\
\hline Prostacyclins & $\begin{array}{c}\text { Bind to endothelial prostacyclin receptors, } \\
\text { increasing Camp which activates protein } \\
\text { kinase A, leading to smooth muscle relaxation } \\
\text { and vasodilatation. }\end{array}$ \\
\hline \multicolumn{2}{|c|}{$\begin{array}{c}\text { Table 1. Mechanism of Action of Drugs- Pulmonary } \\
\text { Vasodilator Therapy(3) }\end{array}$} \\
\hline
\end{tabular}

(Increasing understanding of $\mathrm{PH}$ has led to better treatment and better outcome of PH in pregnancy).

\section{REFERENCES}

[1] Knight M. Kurinczuk JJ, Spark P, et al. United Kingdom Obstetrics Surveillance system (UKOSS) annual Report 2007. Oxford: National Perinatal Epidemiology Unit 2007. 
[2] Weiss BM, Zemp L, Seifert B, et al. Outcome of pulmonary vascular diseases in pregnancy: a systematic overview from 1978 through 1996. J Am Coll Cardiol 1998;31(7):1650-7.

[3] Bedard E, Dimopoulos K, Gatzoulis MA. Has there being any progress made on pregnancy outcomes among women with pulmonary arterial hypertension? Eur heart J 2009;30(3):256-65.
[4] NICE Clinical guidance: caesarean section 2004. http://www.nice.org.uk/nicemedia/pdf/Cg13NICEguida nce.pdf.

[5] RCOG Good Practice No. 13. Cardiac disease and pregnancy. London: Royal College of Obstetricians and Gynaecologists 2011. 